\title{
OVERVIEW AND PREFACE
}

\section{Control of schistosomiasis in sub-Saharan Africa: progress made, new opportunities and remaining challenges}

\author{
J. R. STOTHARD ${ }^{1 *}$, L. CHITSULO ${ }^{2}$, T. K. KRISTENSEN ${ }^{3}$ and J. UTZINGER ${ }^{4}$ \\ ${ }^{1}$ Wolfson Wellcome Biomedical Laboratories, Department of Zoology, Natural History Museum, London, SW7 5BD, UK \\ ${ }^{2}$ Control of Neglected Tropical Diseases, World Health Organization, 20 Avenue Appia, CH-1211 Geneva 27, Switzerland \\ ${ }^{3}$ Mandahl-Barth Research Centre, DBL-Institute for Veterinary Disease Biology, Faculty of Life Sciences, \\ University of Copenhagen, Thorvaldsensvey 57, DK-1871 Frederiksberg, Denmark \\ ${ }^{4}$ Department of Public Health and Epidemiology, Swiss Tropical Institute, P.O. Box, CH-4002 Basel, Switzerland
}

(Received 5 August 2009; accepted 13 August 2009; first published online 9 October 2009)

\section{SUMMARY}

Several other journal supplements have documented progress made in the control of schistosomiasis in Egypt, China and Brazil, however, with more than $97 \%$ of the schistosome infections now estimated to occur in Africa, the relevance of this special issue in Parasitology cannot be overemphasized. In total, 18 articles are presented, inclusive of a lead-editorial from the WHO highlighting a seminal resolution at the 54th World Health Assembly in 2001 that advocated de-worming. Facilitated by a US\$30 million grant from the Bill and Melinda Gates Foundation in 2002, the Schistosomiasis Control Initiative subsequently fostered implementation of large-scale schistosomiasis (and soil-transmitted helminthiasis) control programmes in six selected African countries. From 2005, CONTRAST, a European union-funded consortium, was formed to conduct multi-disciplinary research pertaining to optimisation of schistosomiasis control. Progress made in schistosomiasis control across sub-Saharan Africa since the turn of the new millennium is reviewed, shedding light on the latest findings stemming from clinical, epidemiological, molecular and social sciences research, inclusive of public health interventions with monitoring and evaluation activities. New opportunities for integrating the control of schistosomiasis and other so-called neglected tropical diseases are highlighted, but more importantly, several opportune questions that arise from it frame the remaining challenges ahead for an enduring solution.

Key words: Schistosomiasis, epidemiology, control, preventive chemotherapy, de-worming, public health, Africa.

\section{INTRODUCTION}

For centuries, three countries have been intimately linked with human schistosomiasis: Egypt, China and Brazil. Indeed, the associations go back even further (circa 1900 BC) as evidenced by Egyptian hieroglyphs on papyri and in paintings that might depict blood in urine (endemic haematuria), likely caused by urinary schistosomiasis (Jordan and Webbe, 1969; Jordan, 2000). Firm proof of the occurrence of urinary schistosomiasis in ancient Egypt was obtained by the demonstration of calcified Schistosoma haematobium eggs within the kidneys of two Egyptian mummies dating back over three millennia ago (Adamson, 1976). Most importantly, perhaps, was the discovery in 1851 of adult schistosome worms within a human at autopsy in Cairo by

* Corresponding author: J. Russell Stothard, Wolfson Wellcome Biomedical Laboratories, Department of Zoology, Natural History Museum, London, SW7 5BD, UK. Tel.: + 44207 942-5490; Fax: +44 207 942-5518; E-mail:r.stothard@nhm.ac.uk the German physician Theodor Bilharz, which gave rise to a disease forever associated with his name, bilharzia (Davis, 2009). In China, calcified S. japonicum eggs were demonstrated in two exhumed corpses dating back more than 2000 years (Zhou et al. $2005)$, with the first parasitologically-confirmed case of S.japonicum described by the American physician Oliver T. Logan in 1905 (Utzinger et al. 2005). In Brazil, the first scientific work pertaining to S. mansoni was published in 1908 by the Brazilian physician Pirajá da Silva (Katz, 2008).

It is therefore not surprising that both the public health significance and the socio-economic importance of schistosomiasis have been recognized in Egypt, China and Brazil a long time ago, and that huge efforts have been made to control this chronic and debilitating disease. Indeed, a key feature explaining the successes of the national schistosmiasis control programmes of the aforementioned countries has been better recognition of the public health burden and fostering the necessary political will and leadership for implementing and sustaining 
large-scale interventions (Engels et al. 2002; Wang, Utzinger and Zhou, 2008). Reporting on these achievements, several special issues have been published which provide comprehensive summaries of the epidemiology and control of schistosomiasis in Egpyt, China and Brazil. In 2000, the American Fournal of Tropical Medicine and Hygiene marked the start with a supplement reporting the origins, evolution and main findings of large-scale epidemiological surveys including more than 89000 individuals from 251 rural communities in nine governorates in Egypt (El-Khoby et al. $2000 a, b$ ). This project was implemented from 1990 to 1994 , while schistosomiasis control efforts were already in place and continued thereafter; most notably over 50 million praziquantel treatment courses were administered in Egypt between 1988 and 2001 (Fenwick et al. 2003). A special issue of Acta Tropica, published in 2005, commemorated the 100-year anniversary of the first description of S. japonicum, and highlighted progress made in the control of schistosomiasis in China. While there were an estimated 11.6 million people infected with $S$. japonicum in the mid-1950s, this number was reduced to below a million, half a century later (Utzinger et al. 2005; Zhou et al. 2005). During the 10-year World Bank Loan Project, implemented in the 1990s, praziquantel-based morbidity control was a key pillar of the national control programme with more than 50 million praziquantel treatment courses administered (Chen, 2005). Finally, in 2008, Acta Tropica published another special issue, focusing on schistosomiasis research in Brazil, which coincided with the first description of $S$. mansoni in this country a century ago. The unique contributions of Brazilian clinicians, molecular biologists, epidemiologists and social scientists to further our understanding of the epidemiology and control of schistosomiasis were highlighted (Bergquist, 2008). From a public health point of view, the large-scale administration of the antischistosomal drug oxamniquine in the national schistosomiasis control programme of Brazil is of particular mention; more than 12 million treatment courses were administered before gradually replacing oxamniquine with praziquantel (Katz and Coelho, 2008).

In this special issue of Parasitology, the control of schistosomiasis in sub-Saharan Africa is featured. Justification for such a special issue derived from the following grounds:

- recognizing the public health importance and sheer magnitude of schistosomiasis on this continent (WHO, 2002);

- realizing the growing evidence that the risk of schistosomiasis has increased due to water resources development and management in the absence of comprehensive mitigation measures (Steinmann et al. 2006);
- growing international interest and advocacy and changing funding landscape with new opportunities to conquer schistosomiasis and other socalled neglected tropical diseases (Fenwick, 2006; Hotez et al. 2007); and

- issuing a note of caution that renewed efforts to control schistosomiasis and sustain interventions are not allowed to falter (Utzinger et al. 2003).

The papers in this special issue summarize scientific advances and progress made in the control of schistosomiasis in sub-Saharan Africa since the turn of the new millennium, highlighting current and future opportunities to optimize schistosomiasis control and transmission surveillance. Also discussed are the scope and limits for integrating the control of schistosomiasis with other neglected tropical diseases. From these new opportunities a host of opportune questions arise and several remaining challenges are identified. The special issue consists of the current overview along with 18 contributions, about half review-style pieces complemented with original research and an editorial. The manuscripts have been prepared by experts in epidemiology, molecular parasitology, public health and social sciences based across Africa. Most articles are coauthored with colleagues from Africa and Europe, demonstrating the existing and productive research partnerships between universities, Ministries of Health $(\mathrm{MoH})$ and non-governmental organizations (NGOs) in the South and partner institutions in the North and international organizations, most notably the World Health Organization (WHO).

SCHISTOSOMIASIS IN SUB-SAHARAN AFRICA

\section{In the summer of ' 69}

Exactly 40 years have elapsed since the publication of Human Schistosomiasis by Peter Jordan and Gerald Webbe; a seminal monograph, which carefully outlined all the then known ingredients for control of schistosomiasis (Jordan and Webbe, 1969). At a time when the world's attention was captured by the lunar landscape, a global optimism grew that with the right technology and political commitment almost anything was possible - a man could even walk on the Moon - and to share and communicate this precise moment in time, the peoples of the Earth were brought together by television on 20 July 1969 to witness the Apollo 11 landing on the Moon, broadcast to at least 600 million people around the globe although only a privileged few witnessed this event from subSaharan Africa. Indeed, the moment saw the fruition of former US president John F. Kennedy's vision, aired in the early 1960 s, to safely land a man on the Moon and to bring him back to Earth before the end of the decade, but it is perhaps interesting to note at what financial cost the 13-year Apollo programme 
incurred. According to the National Aeronautics and Space Administration (NASA), the estimated cost of the Apollo programme was US\$ 135 billion, as expressed in 2005 US\$ (NASA, 2009), which sets an interesting funding barometer to measure against present financial contributions for control of schistosomiasis and other neglected tropical diseases in Africa and elsewhere in the developing world.

Less than a month after the Moon landing, the legendary Woodstock Festival took place from 15-18 August 1969 in the state of New York-perhaps defining the start of a new socio-political era where an individual's right to drugs and medications, either rightly or wrongly procured, was fervently debated. Indeed equitable access to medications in the United States of America, sub-Saharan Africa and elsewhere continues to engender substantial debate and in this special issue we see the arguments further taking form.

\section{Paradigm shift in the mid-1980s}

In the 1970 s and the early 1980 s, transmission control, inclusive of mollusciciding and environmental management, remained the strategy of choice to combat schistosomiasis, although there was a growing arsenal of safe and efficacious antischistosomal drugs. The advent of praziquantel in the second half of the 1970s (Seubert, Pohlke and Loebich, 1977), the rapid demonstration of the excellent safety and efficacy profile of praziquantel against all human schistosome species in multi-centric trials (Davis and Wegner, 1979), and first experiences gained with the large-scale administration of this drug in Mali (Brinkmann et al. 1988) and Malawi (Wolff and Malewezi, 1989) eventually led to a paradigm shift. Indeed, in the mid-1980s, WHO endorsed praziquantel-based morbidity control as the new global strategy against schistosomiasis (WHO, 1985). The first two national schistosomiasis control programmes carried out on the African continent were implemented as vertical programmes. Given the high price for praziquantel (approximately US\$ 1 per $600 \mathrm{mg}$ tablet), major external donor support was necessary, and it was granted by the German Technical Cooperation, GTZ in short. The central feature of these schistosomiasis control programmes was praziquantel-based morbidity control, whereas health education and improving sanitation were complementary measures (Brinkmann et al. 1988; Wolff and Malewezi, 1989).

\section{The May 2001 World Health Assembly}

In the 1990s, the vertically-managed schistosomiasis control programmes of Mali and Malawi were decentralized and efforts made to integrate control activities into the MoH. However, there were rapid recrudescences and infection prevalences soon reached pre-intervention levels, and hence these programmes failed to demonstrate sustainability (Utzinger et al. 2003). Elsewhere in sub-Saharan Africa there was a lack of interest, political will and leadership, and financial resources were absent or insufficient to launch new national schistosomiasis control programmes. Access to praziquantel therefore remained elusive for most of the people in need, which is partially explained by the high price of the drug at this time, which placed it out of reach of many ministerial budgets.

Despite these contextual determinants and economic reasons, the experiences and successes of large-scale chemotherapy-based morbidity control programmes in Egypt, China and Brazil (Fenwick et al. 2003; Utzinger et al. 2005; Katz and Coelho, 2008) resulted in a sea change of schistosomiasis control. On 22 May 2001, during the 54th World Health Assembly (WHA) held at WHO headquarters in Geneva, WHA Resolution 54.19 was endorsed. Among other issues, member states were urged to attain " a minimum target of regular administration of chemotherapy to at least $75 \%$ and up to $100 \%$ of all school-age children at risk of morbidity by 2010" (WHO, 2002). The importance of this resolution was prominently featured in a policy forum published later in 2001 in Science while, at the same time, the danger was expressed that such large-scale drug campaigns might jeopardize new research as the control and subsequent elimination of schistosomiasis might seem just around the corner (Colley, LoVerde and Savioli, 2001). In any event, the developments that lead to the endorsement of WHA Resolution 54.19 and the visionary thinking behind it are summarized in an accompanying editorial put forth by colleagues from WHO (Savioli et al. 2009). Most importantly, integrated control of schistosomiasis and soil-transmitted helminthiasis was recommended with a detailed plan of action published in the following year; the 57-page WHO Technical Report Series No. 912 (WHO, 2002). Justification for concurrently tackling morbidity due to schistosomiasis and soil-transmitted helminthiasis was based on the following grounds:

- schistosomiasis and soil-transmitted helminthiasis are co-endemic over large parts of the developing world;

- school-aged children are at highest risk of morbidity due to schistosomiasis and soil-transmitted helminthiasis;

- school-aged children (those attending school and non-attending siblings) can be reached readily through the existing education system; and

- there is a common intervention strategy that can be implemented with the assistance of school teachers, namely the large-scale administration of safe and efficacious anthelminthic drugs (praziquantel against schistosomiasis and albendazole 
or mebendazole against soil-transmitted helminthiasis).

Retrospectively, WHA Resolution 54.19 and the subsequent WHO Technical Report Series No. 912 can be considered as the precursors for new proposals recommending integrated control of multiple neglected tropical diseases (Molyneux, Hotez and Fenwick, 2005; Fenwick, 2006; Hotez et al. 2006; Utzinger and de Savigny, 2006). The prospect and challenges of the contemporary initiatives for integrated control of neglected tropical diseases have been discussed (Brady, Hooper and Ottesen, 2006; Lammie, Fenwick and Utzinger, 2006; Richards et al. 2006; Kolaczinski et al. 2007; Parker, Allen and Hastings, 2008; Rumunu et al. 2009).

In this current special issue, the need and future directions for an integrated rapid mapping approach for multiple neglected tropical diseases are outlined (Brooker et al. 2009). Moreover, words of caution are expressed, since the potential benefits and achievements that can be expected with preventive chemotherapy alone might be overstated, particularly after the initial stage of control which is the reduction of morbidity (Utzinger et al. 2009). In the long run, one must think beyond preventive chemotherapy (Anonymous, 2004). Indeed, truly integrated control approaches will be required, hence complementing large-scale drug administration with preventive measures (e.g. locallyadapted information, education and communication strategies, improved access to clean water and adequate sanitation), alongside strengthening of health systems and fostering intersectoral collaboration (Utzinger et al. 2003, 2009; Holveck et al. 2007; Singer and Castro, 2007). Recent experiences in China, employing a comprehensive intervention package to control the transmission of S. japonicum, can stimulate national schistosomiasis control programmes elsewhere. Issuing from WHA Resolution 54.19 , alongside recommendations for the frequency of anthelminthic treatment (praziquantel against schistosomiasis and albendazole or mebendazole against soil-transmitted helminthiasis), according to disease endemicity thresholds, are national and regional treatment needs that are critically discussed in this special issue (Utzinger et al. 2009).

\section{The 2002 launch of the Schistosomiasis Control Initiative}

In 2002, facilitated by a generous start-up grant of US\$ 30 million from the Bill and Melinda Gates Foundation, the Schistosomiasis Control Initiative (SCI) was established. Clearly, SCI was the most significant response to the call of action put forth in WHA Resolution 54.19. Indeed, SCI was at the root of assisting six African countries (Burkina Faso, Mali, Niger, Uganda, United Republic of Tanzania and Zambia) that had been carefully selected based upon schistosomiasis endemicity levels and the countries' proposals for setting up and implementing national schistosomiasis and soil-transmitted helminthiasis control programmes. Fig. 1 shows the estimated country-specific schistosome prevalence data across Africa as of mid-2003, according to webappendix 2 from a recent review (Steinmann et al. 2006). The estimated schistosome prevalence was above $50 \%$ in three of the SCI-supported countries (Burkina Faso, Mali and United Republic of Tanzania), whereas the respective prevalence estimates were around $25 \%$ in the remaining three countries (Niger, Uganda and Zambia). Were schistosome endemicity estimates taken as the sole criteria for country selection, Ghana, Madagascar, Mozambique and Sierra Leone should have been further considered. Of note are a new US\$ 100 million initiative granted through the United States Agency for International Development (USAID), and $\& 50$ million pledged support by the UK Department for International Development and US\$ 350 millions from the US Government in 2008 (Hotez et al. 2009) which should result in stepping up integrated control efforts targeting multiple neglected tropical diseases in the previously SCIsupported countries (Garba et al. 2009) and other sub-Saharan African countries where neglected tropical diseases are still rampant.

The rationale, development and implementation, including the annual number of praziquantel treatments administered in each country, monitoring activities and proposed exit strategies are described in the 'SCI-story' featured in this special issue (Fenwick et al. 2009). The first treatment round commenced in 2003 and targeted half a million people, mainly in the pilot control programme in Uganda. In 2005, close to 13 million doses of praziquantel were administered in the six SCI-supported countries and, by the end of 2008, a total of 45 million praziquantel treatments were administered. The SCI-supported control programmes confirmed that in most settings it was possible to reach schoolaged children and to treat them with praziquantel and albendazole for less than US\$ 0.5 per capita and per year. Whilst the total amount utilized for schistosomiasis control is impressive, it is telling, however, that the 4-year US\$ 30 million start-up funding from the Bill and Melinda Gates Foundation for SCI translates to only a small fraction of a percentage point $(0.02 \%)$ when compared to the 13-year Apollo lunar mission programme.

\section{In 2005 : the CONTRAST research consortium}

Concern had been expressed shortly after issuing WHA Resolution 54.19 that large-scale preventive chemotherapy-based control programmes against schistosomiasis and other helminthic diseases might 


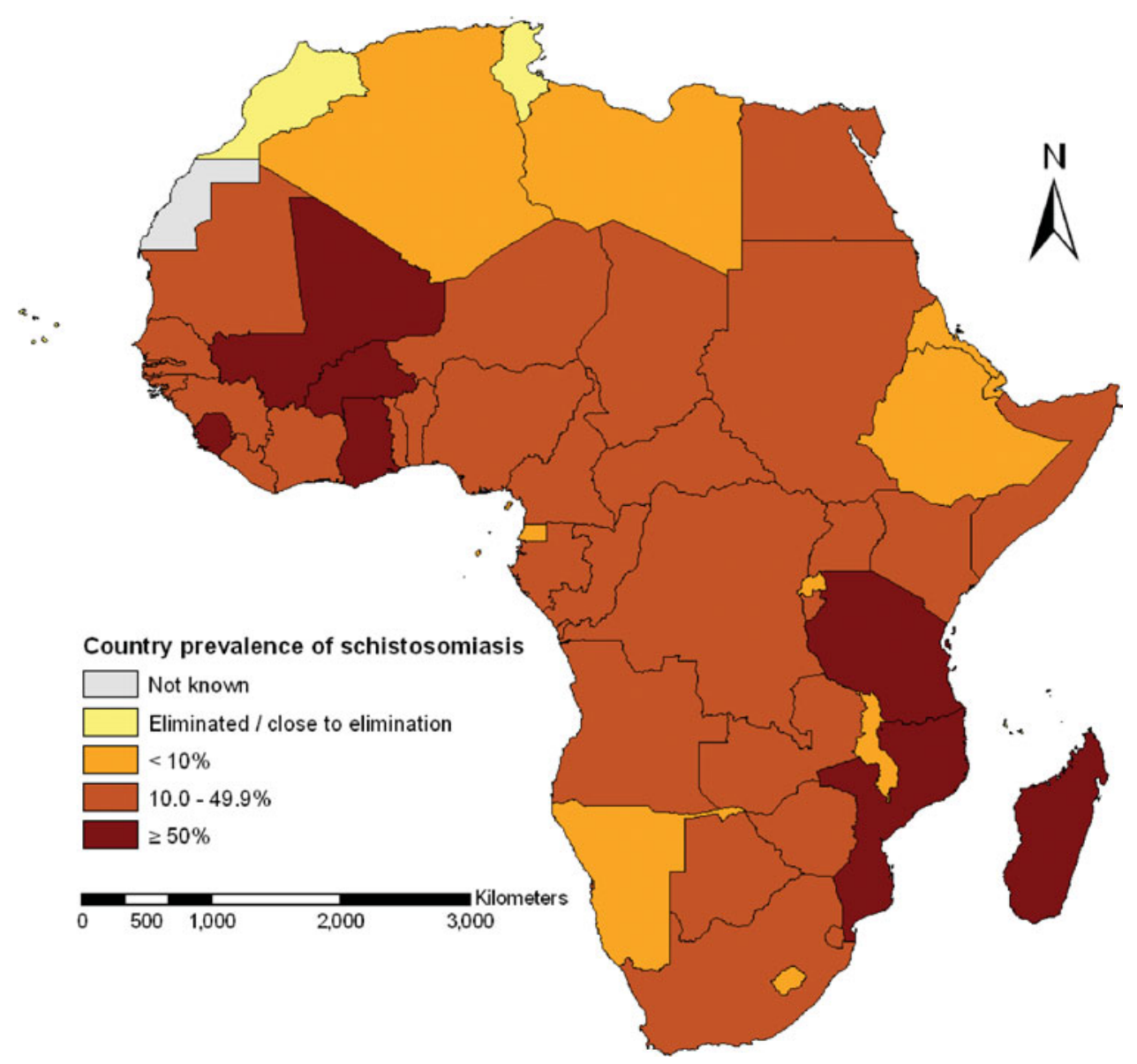

Fig. 1. Country-specific prevalence estimates for schistosomiasis across Africa as of mid-2003 (data obtained from webappendix 2 from Steinmann et al. 2006).

lower enthusiasm, financial commitment and general interest for basic and operational research (Colley et al. 2001). However, an important lesson learnt from the schistosomiasis control programmes in Egypt, China and Brazil was that an integral research component would sustain control interventions and facilitate future progress as the challenge of control will change from morbidity control to transmission containment and ultimately elimination (Utzinger et al. 2005; Bergquist, 2008). Against this background, a multidisciplinary alliance was formed in 2005 in Zanzibar with the goal to optimize schistosomiasis control and transmission surveillance across sub-Saharan Africa. The project was funded by the European Union with a 4-year grant of $€ 2.9$ million and is known under the acronym CONTRAST (http://www.eu-contrast.eu/) and a key feature of the consortium was the strengthening of institutional partnerships through establishment of an enduring infrastructure for research with development of five specialist research nodes across Africa to foster cross-country research. The research nodes can be summarized as follows:

- a snail-parasite laboratory in Cameroon;

- a molecular DNA laboratory in Uganda;

- a biological reference collection centre in Kenya;
- a demographic and socio-economic centre in the United Republic of Tanzania; and

- a remote sensing and spatial epidemiology laboratory in Zambia.

Importantly, each research node has been twinned with a mutually supporting European partner institution in order to pair similar sets of interest and skill-bases to strengthen and further enhance research partnerships over a longer-term perspective. This special issue and a number of the preceding publications document fruition of the specialist research node structure facilitated through the CONTRAST programme. Regarding molecular research, a DNA barcoding approach has been employed for the identification and classification of Bulinus spp., the intermediate host snail of $S$. haematobium (Kane et al. 2008), and revealed considerable genetic diversity both in schistosomes and its intermediate host snails in Uganda (Rollinson et al. 2009; Stothard et al. 2009). Regarding demographic and socio-economic investigations, the literature has been reviewed and highlights the role of the social sciences to further our understanding of the epidemiology and control of schistosomiasis in Africa (Aagaard-Hansen, Mwanga and Bruun, 2009). Finally, with regard to remote sensing and 
spatial epidemiology, CONTRAST is in the process of developing an open-access georeferenced database on parasite and snail surveys carried out in Africa (Simoonga et al. 2009; Stensgaard et al. 2009) and uses advanced Bayesian geospatial models to map and predict the risk of schistosomiasis prevalence and infection intensity data (Vounatsou et al. 2009).

\section{The 2009 developments : schistosome genomes and SCORE}

In mid-2009, the research community has witnessed the fruition of another scientific milestone, as the current special issue to Parasitology is preceded by the publication of the 363 megabase nuclear genome of S. mansoni in Nature (Berriman et al. 2009), alongside the draft genomic sequence of $S$. japonicum (The Schistosoma japonicum Genome Sequencing and Functional Analysis Consortium, 2009). An important motivation to analyse the molecular architecture of these two blood flukes was the pressing need to discover and develop new antischistosomal drug targets. Indeed, the treatment and control of schistosomiasis virtually relies on a single tool, praziquantel (Caffrey, 2007; Danso-Appiah et al. 2009; Doenhoff, Cioli and Utzinger, 2008; Doenhoff et al. 2009). While the two Nature articles provide major new insights into the biology and evolution of $S$. mansoni and $S$. japonicum, and identify a host of parasite proteins that might be harnessed to discover new antischistosomal drug lead candidates, they also highlight differences between the genomes of these two schistosome species. It has been noted elsewhere that there is currently insufficient genome and transcriptome information for the third major schistosome species, S. haematobium (Rollinson, 2009). Moreover, there is a paucity of in vitro and in vivo research pertaining to $S$. haematobium, which is a major hindering factor for focused discovery and development research to fill the antischistosomal drug pipeline (Doenhoff et al. 2009).

Last but not least, with new insight gained at a molecular level, a host of operational research questions remain and new ones arise, particularly in view of growing emphasis on preventive chemotherapy targeting multiple neglected tropical diseases simultaneously. Among other issues, the optimal timing of praziquantel administration needs further refinement and a detailed understanding of transmission dynamics is key (Augusto et al. 2009). Moreover, the most suitable and locally-accepted delivery strategies for large-scale administration of anthelminthic drugs (e.g. school-based or community-based approach) need to be evaluated, including issues of coverage, cost-effectiveness and sustainability (Massa et al. 2009). Some of these operational research questions will be addressed through the Schistosomiasis Consortium for Operational Research and
Evaluation (SCORE), funded by the Bill and Melinda Gates Foundation.

\section{A PREFACE TO THIS SPECIAL ISSUE}

OF PARASITOLOGY

Bringing together the current overview, an editorial by WHO and 17 original research articles and reviews, has seen the co-operation, help and support from not less than 75 contributing authors, mainly from Africa and Europe (Fig. 2). Seven of these papers feature an African as first author, which represents a much more equitable authorship configuration than what is usually seen in the core tropical medicine literature (Keiser et al. 2004). Balancing both basic and operational research, as well as highlighting progress and pit-falls of schistosomiasis control in sub-Saharan Africa has been a formidable challenge. However, the truly international partnership in operation here, with many of the contributing authors working in formal research partnerships based within institutions that bridge North and South areas of the world, served as the platform to facilitate this endeavour. Most importantly the authors represent not only experts in their particular field but also key advocates and proponents of ongoing neglected tropical disease control programmes. For example, many are working at the coal-face of national interventions in sub-Saharan Africa and by sharing their advice and experiences is, we believe, an important future testimony for decades to come.

In producing this special issue, we must first firmly acknowledge Dr. Les Chappell, the co-ordinating editor, who has been able to guide us all through this highly evolved, electronic world of scientific publishing. Indeed, Les's efforts have been herculean in keeping up to date with all the numerous e-mails passing through his office and we are especially grateful to Cambridge University Press for their generous support in bringing this project to fruition.

A particularly prophetic comment made by Jordan and Webbe in their 1969 monograph, which holds true today was "It is likely that the provision of adequate funds and properly trained personnel will only result from the adoption of control programmes at a national level with the possible assistance of international agencies" and sets a theme throughout this special issue. It is thus implicit that countries should, with appropriate external support where necessary, best grow their own national plans largely by themselves to scale-up activities and take significant steps to better implement and harmonise all intervention activities. Indeed, Human Schistosomiasis is generally acknowledged to have had a profound impact upon the public health interventions of today, but few could have predicted that morbidity control through large-scale administration of anthelminthic drugs - a strategy now termed 'preventive 


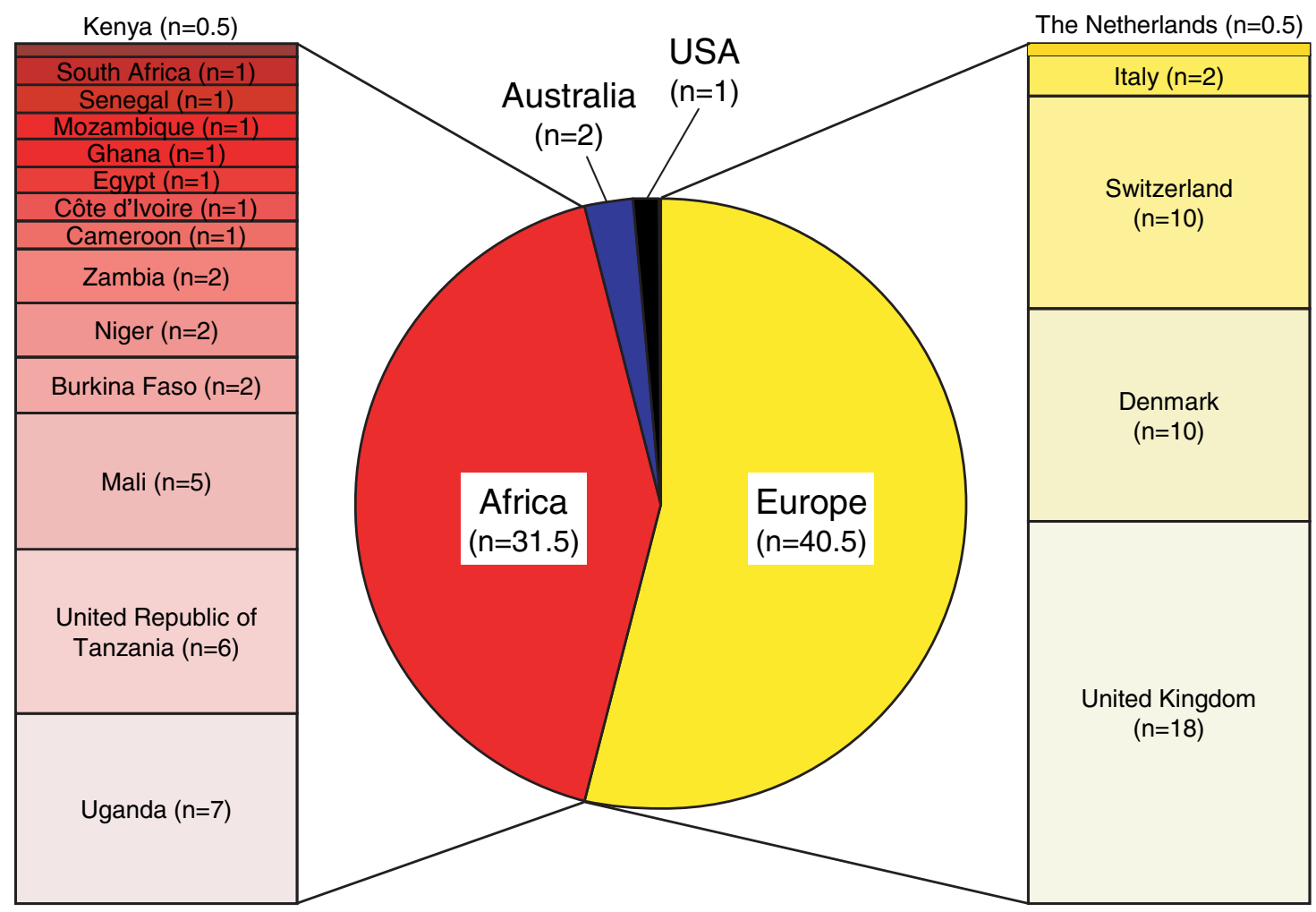

Fig. 2. Geographical analysis according to author affiliations of the 75 contributing authors to this special issue of Parasitology. Please note that if an author is affiliated to two different countries, each country is counted only half, which explains that the Netherlands and Kenya reached only $0 \cdot 5$.

chemotherapy'- would increasingly take centre stage to become the mainstay and arguably the most pragmatic public health intervention of today's measures against schistosomiasis and other neglected tropical diseases (WHO, 2006; Hotez et al. 2007). Such a change has created new opportunities for control which seemingly outshine those based upon improving sanitation and better water hygiene alone, which were then given greater favour. However, the fundamental role of economic development, which will foster improved access to clean water and adequate sanitation cannot be overemphasised and will ultimately lead to sustainable control of schistosomiasis and a host of other helminthic, bacterial and viral diseases.

From the new opportunities, a number of opportune questions arise, most importantly: "What is the exact and lasting endurance of such recent initiatives?" This special issue has been structured in five sections in a way to group papers reflecting several most pertinent issues. Following the WHO editorial emphasising the development and further evolution of WHA Resolution 54.19 (Savioli et al. 2009), a first section of three papers follows that discuss issues of implementing control interventions at different spatial scales (Brooker et al. 2009; Simoonga et al. 2009; Vounatsou et al. 2009). With the often patchy, focal distribution of schistosomiasis and other neglected tropical diseases, there are new challenges for rapid identification of disease risk not only using space satellite-based technologies but also in 'ground-truthing' these data for estimation of actual numbers to be treated through time. Creation of useful spatially-explicit databases that enable disease control managers and stakeholders to make informed decisions is becoming ever more crucial to enhance the cost-effectiveness of control. In addition, feeding this information accurately to international agencies is also vital to ensure that the global supply chain of medications does not become choked.

The second section with another three papers highlights and reviews the considerable progress that has been made in the control of schistosomiasis and soil-transmitted helminthiasis at the national level, with or without SCI support (Fenwick et al. 2009; Garba et al. 2009; Tchuem Tchuenté and N'Goran, 2009). It appears that intersectoral co-operation and collaboration is essential, yet not always easy to achieve. A significant future challenge will be to develop and sustain the necessary cadre of staff to be able to implement each intervention in an equitable and harmonised way.

Immediate areas of programmatic optimisation are identified in the third section consisting of four papers (Aagaard-Hansen et al. 2009; Augusto et al. 2009; Fleming et al. 2009; Massa et al. 2009). For example, ways are fostered to encourage better compliance and timing of praziquantel treatment 
within the recipient community. Since monitoring and evaluation of any intervention are essential steps within any large-scale programme, the papers in the fourth section emphasise the interaction between research and control from the molecular to the population level (Rollinson et al. 2009; Stothard et al. 2009; Webster et al. 2009). In particular, attention is drawn to dynamics of disease morbidity indicators as well as schistosome and intermediate host snail population dynamics. In the fifth and final section, the unique properties of praziquantel are stressed (safety, efficacy and low cost) and the tremendous role this antischistosomal drug has played for morbidity control of schistosomiasis around the world is highlighted (Doenhoff et al. 2008; Danso-Appiah et al. 2009; Sacko et al. 2009; Utzinger et al. 2009). The pressing need for development of novel antischistosomal drugs and the strengthening of health systems that will serve as the platforms to facilitate integrated control of neglected tropical disease in the future are discussed.

\section{CONCLUDING REMARKS}

It should be recognised that for an enduring impact against schistosomiasis and other helminthic diseases the vista for control should be seen from a perspective of several decades of sustained intervention, and not in years as often dictated by the donor-agencies. One must also remember that in areas where permissive snail intermediate hosts commonly occur, levels of environmental transmission might be slow to dampen even with effective chemotherapy. With this suite of 18 papers the present and future history of control of schistosomiasis in sub-Saharan Africa is far from complete as the story is yet unfolding and much more could be achieved with better molluscan control. In Africa nothing is ever certain, and at the national level, the political stability in certain sub-Saharan countries is a very relative concept which, in turn, determines whether sustainable interventions stand or fall. From another outlook, the international financial fundingbase necessary to sustain the present set of national control programmes, through donated funds and drugs, has not yet stabilised and is still only a small fraction of what is actually needed. With the recent global economic down-turn further erosion of resources for control will likely increase as financial uncertainties, especially that of governments as well as donor-agencies themselves, grow.

Bringing together and firmly securing all the necessary ingredients to ensure programmatic sustainability for continuous control of schistosomiasis in sub-Saharan Africa is sadly not yet within reach. However, the increasing advocacy and massive scale-up of large-scale drug-based control programmes have already resulted in significant reductions of morbidity due to lymphatic filariasis, onchocerciasis and soil-transmitted helminthiasis, which bodes well for morbidity control of schistosomiasis. This will be felt especially where equitable partnerships between agencies are formed and where interventions can be more and more integrated into the existing health system rather than creating parallel vertical structures alongside it. It is our hope that when the first human will set foot on planet Mars, the control of schistosomiasis in sub-Saharan Africa will have shifted from morbidity control to transmission control, or even local elimination, and at the same time leave behind aquatic environments rich in biological diversity, for generations to come.

\section{ACKNOWLEDGEMENTS}

We are grateful to Cambridge University Press and Dr. Les Chappell, editor of Parasitology and co-ordinating editor of this special issue for their generous support, expertise and unlimited assistance, which were key factors to bring this project to fruition. We express our deep thanks to all the authors, colleagues and friends for their great contributions and leadership in schistosomiasis research and disease control interventions, often under difficult circumstances. We thank Nadine Riedel for her help with Figure 1 and Mirko Winkler for his assistance to rapidly search electronic databases in relation to the Moon landing. J. R. Stothard acknowledges funding from the Wellcome Trust and former employment within SCI. J. Utzinger is grateful to the Swiss National Science Foundation for continued financial support (project no. PPOOB-102883; PPOOB-119129). The EUCONTRAST (project number 032203) consortium provides project support for J. R. Stothard, T. K. Kristensen and J. Utzinger.

\section{REFERENCES}

Aagaard-Hansen, J., Mwanga, J. R. and Bruun, B. (2009). Social science perspectives on schistosomiasis control in Africa: past trends and future directions. Parasitology 136, 1747-1758.

Adamson, P. B. (1976). Schistosomiasis in antiquity. Medical History 20, 176-188.

Anonymous (2004). Thinking beyond deworming. Lancet 364, 1993-1994.

Augusto, G., Magnussen, P., Kristensen, T. K., Appleton, C. C. and Vennervald, B. J. (2009). The influence of transmission season on parasitological cure rates and intensity of infection after praziquantel treatment of Schistosoma haematobium-infected schoolchildren in Mozambique. Parasitology 136, 1771-1779.

Bergquist, R. (2008). A century of schistosomiasis research. Acta Tropica 108, 65-68.

Berriman, M., Haas, B. J., LoVerde, P. T., Wilson, R. A., Dillon, G. P., Cerqueira, G. C., Mashiyama, S. T., Al-Lazikani, B., Andrade, L. F., Ashton, P. D., Aslett, M. A., Bartholomeu, D. C., Blandin, G., Caffrey, C. R., Coghlan, A., Coulson, R., Day, T. A., Delcher, A., DeMarco, R., Djikeng, A., Eyre, T., Gamble, J. A., Ghedin, E., Gu, Y., Hertz-Fowler, C., Hirai, H., Hirai, Y., Houston, R., Ivens, A., Johnston, D. A., Lacerda, D., Macedo, C. D., 
McVeigh, P., Ning, Z., Oliveira, G., Overington, J. P., Parkhill, J., Pertea, M., Pierce, R. J.,

Protasio, A. V., Quail, M. A., Rajandream, M. A., Rogers, J., Sajid, M., Salzberg, S. L., Stanke, M., Tivey, A. R., White, O., Williams, D. L., Wortman, J., Wu, W., Zamanian, M., Zerlotini, A.,

Fraser-Liggett, C. M., Barrell, B. G. and El-Sayed, N. M. (2009). The genome of the blood fluke Schistosoma mansoni. Nature 460, 352-358.

Brady, M. A., Hooper, P. J. and Ottesen, E. A. (2006). Projected benefits from integrating NTD programs in sub-Saharan Africa. Trends in Parasitology 22, 285-291.

Brinkmann, U. K., Werler, C., Traoré, M. and Korte, R. (1988). The national schistosomiasis control programme in Mali, objectives, organization, results. Tropical Medicine and Parasitology 39, 157-161.

Brooker, S., Kabatereine, N. B., Gyapong, J. O., Stothard, J. R. and Utzinger, J. (2009). Rapid mapping of schistosomiasis and other neglected tropical diseases in the context of integrated control programmes in Africa. Parasitology 136, 1707-1718.

Caffrey, C. R. (2007). Chemotherapy of schistosomiasis: present and future. Current Opinion in Chemical Biology 11, 433-439.

Chen, M. G. (2005). Use of praziquantel for clinical treatment and morbidity control of schistosomiasis japonica in China: a review of 30 years' experience. Acta Tropica 96, 168-176.

Colley, D. G., LoVerde, P. T. and Savioli, L. (2001). Medical helminthology in the 21st century. Science 293, 1437-1438.

Danso-Appiah, A., Garner, P., Olliaro, P. L. and Utzinger, J. (2009). Treatment of urinary schistosomiasis: methodological issues and research needs identified through a Cochrane systematic review. Parasitology 136, 1837-1849.

Davis, A. (2009). Schistosomiasis. In Manson's Tropical Diseases (eds Cook, G. C. and Zumla A. I.), Saunders Elsevier, pp. 1425-1460.

Davis, A. and Wegner, D. H. (1979). Multicentre trials of praziquantel in human schistosomiasis: design and techniques. Bulletin of the World Health Organization 57, 767-771.

Doenhoff, M. J., Cioli, D. and Utzinger, J. (2008). Praziquantel: mechanisms of action, resistance and new derivatives for schistosomiasis. Current Opinion in Infectious Diseases 21, 659-667.

Doenhoff, M. J., Hagan, P., Cioli, D., Southgate, V., Pica-Mattoccia, L., Botros, S., Coles, G., Tchuem Tchuenté, L. A., Mbaye, A. and Engels, D. (2009). Praziquantel: its use in control of schistosomiasis in sub-Saharan Africa and current research needs. Parasitology 136, 1825-1835.

El-Khoby, T., Galal, N., Fenwick, A., Barakat, R., El-Hawey, A., Nooman, Z., Habib, M., Abdel-Wahab, F., Gabr, N. S., Hammam, H. M. Hussein, M. H., Mikhail, N. N., Cline, B. L. and Strickland, G. T. $(2000 a)$. The epidemiology of schistosomiasis in Egypt: summary findings in nine governorates. American Fournal of Tropical Medicine and Hygiene 62 (2 Suppl.), 88-99.

El-Khoby, T., Hussein, M. H., Galal, N. and Miller, F. D. $(2000 b)$. Epidemiology 1, 2, 3: origins, objectives, organization, and implementation. American Fournal of Tropical Medicine and Hygiene 62 (2 Suppl.), 2-7.

Engels, D., Chitsulo, L., Montresor, A. and Savioli, L. (2002). The global epidemiological situation of schistosomiasis and new approaches to control and research. Acta Tropica 82, 139-146.

Fenwick, A. (2006). New initiatives against Africa's worms. Transactions of the Royal Society of Tropical Medicine and Hygiene 100, 200-207.

Fenwick, A., Savioli, L., Engels, D., Bergquist, N. R. and Todd, M. H. (2003). Drugs for the control of parasitic diseases: current status and development in schistosomiasis. Trends in Parasitology 19, 509-515.

Fenwick, A., Webster, J. P., Bosque-Oliva, E., Blair, L., Fleming, F. M., Zhang, Y., Garba, A., Stothard, J. R., Gabrielli, A. F., Clements, A. C. A., Kabatereine, N. B., Toure, S., Dembele, R., Nyandindi, U., Mwansa, J. and Koukounari, A. (2009). The Schistosomiasis Control Initiative (SCI): rationale, development and implementation from 2002-2008. Parasitology 136, 1719-1730.

Fleming, F. M., Fenwick, A., Tukahebwa, E. M., Lubanga, R. G. N., Namwangye, H., Zaramba, S. and Kabatereine, N. B. (2009). Process evaluation of schistosomiasis control in Uganda, 2003 to 2006 : perceptions, attitudes and constraints of a national programme. Parasitology 136, 1759-1769.

Garba, A., Toure, S., Dembele, R., Boisier, P., Tohon, Z., Bosque-Oliva, E., Koukounari, A. and Fenwick, A. (2009). Present and future schistosomiasis control activities with support from the Schistosomiasis Control Initiative in West Africa. Parasitology 136, 1731-1737.

Holveck, J. C., Ehrenberg, J. P., Ault, S. K., Rojas, R., Vasquez, J., Cerqueira, M. T., Ippolito-Shepherd, J., Genovese, M. A. and Periago, M. R. (2007). Prevention, control, and elimination of neglected diseases in the Americas: pathways to integrated, inter-programmatic, inter-sectoral action for health and development. BMC Public Health 7, 6.

Hotez, P. J., Fenwick, A., Savioli, L. and Molyneux, D. H. (2009). Rescuing the bottom billion through control of neglected tropical diseases. Lancet 373, 1570-1575.

Hotez, P. J., Molyneux, D. H., Fenwick, A., Kumaresan, J., Ehrlich Sachs, S., Sachs, J. D. and Savioli, L. (2007). Control of neglected tropical diseases. New England Fournal of Medicine 357, 1018-1027.

Hotez, P. J., Molyneux, D. H., Fenwick, A., Ottesen, E., Ehrlich Sachs, S. and Sachs, J. D. (2006). Incorporating a rapid-impact package for neglected tropical diseases with programs for HIV/AIDS, tuberculosis, and malaria. PLoS Medicine 3, e102.

Jordan, P. (2000). From Katayama to the Dakhla Oasis: the beginning of epidemiology and control of bilharzia. Acta Tropica 77, 9-40.

Jordan, P. and Webbe, G. (1969). Human Schistosomiasis. William Heinemann Medical Books Ltd, London.

Kane, R. A., Stothard, J. R., Emery, A. M. and Rollinson, D. (2008). Molecular characterization 
of freshwater snails in the genus Bulinus: a role for barcodes? Parasites and Vectors 1, 15.

Katz, N. (2008). The discovery of schistosomiasis mansoni in Brazil. Acta Tropica 108, 69-71.

Katz, N. and Coelho, P. M. Z. (2008). Clinical therapy of schistosomiasis mansoni: the Brazilian contribution. Acta Tropica 108, 72-78.

Keiser, J., Utzinger, J., Tanner, M. and Singer, B. H. (2004). Representation of authors and editors from countries with different human development indexes in the leading literature on tropical medicine: survey of current evidence. British Medical fournal 328, 1229-1232.

Kolaczinski, J. H., Kabatereine, N. B., Onapa, A. W., Ndyomugyenyi, R., Kakembo, A. S. and Brooker, S. (2007). Neglected tropical diseases in Uganda: the prospect and challenge of integrated control. Trends in Parasitology 23, 485-493.

Lammie, P. J., Fenwick, A. and Utzinger, J. (2006). A blueprint for success : integration of neglected tropical disease control programmes. Trends in Parasitology 22, 313-321.

Massa, K., Olsen, A., Sheshe, A., Ntakamulenga, R., Ndawi, B. and Magnussen, P. (2009). Can coverage of schistosomiasis and soil-transmitted helminthiasis control programmes targeting school-aged children be improved? New approaches. Parasitology 136, 1781-1788.

Molyneux, D. H., Hotez, P. J. and Fenwick, A. (2005). "Rapid-impact interventions": how a policy of integrated control for Africa's neglected tropical diseases could benefit the poor. PLoS Medicine 2, e336.

NASA (2009). The Apollo Spacecraft: A Chronology, vols. 1-4, NASA SP-4009. In http://www.hq.nasa.gov/ office/pao/History/SP-4214/app2.html Washington, 1969-1978.

Parker, M., Allen, T. and Hastings, J. (2008). Resisting control of neglected tropical diseases: dilemmas in the mass treatment of schistosomiasis and soil-transmitted helminths in north-west Uganda. Fournal of Biosocial Science 40, 161-181.

Richards, F. O., Jr., Eigege, A., Miri, E. S., Jinadu, M. Y. and Hopkins, D. R. (2006). Integration of mass drug administration programmes in Nigeria: the challenge of schistosomiasis. Bulletin of the World Health Organization 84, 673-676.

Rollinson, D. (2009). A wake up call for urinary schistosomiasis: reconciling research effort with public health importance. Parasitology 136, 1593-1610.

Rollinson, D., Webster, J. P., Webster, B., Nyakaana, S., Jorgensen, A. and Stothard, J. R. (2009). Genetic diversity of schistosomes and snails: implications for control. Parasitology 136, 1801-1811.

Rumunu, J., Brooker, S., Hopkins, A., Chane, F., Emerson, P. and Kolaczinski, J. (2009). Southern Sudan: an opportunity for NTD control and elimination? Trends in Parasitology 25, 301-307.

Sacko, M., Magnussen, P., Traore, M., Landoure, A., Doucoure, A., Reimert, C. M. and Vennervald, B. J. (2009). The effect of single dose versus two doses of praziquantel on Schistosoma haematobium infection and pathology among school-aged children in Mali. Parasitology 136, 1851-1857.
Savioli, L., Gabrielli, A. F., Montresor, A., Chitsulo, L. and Engels, D. (2009). Schistosomiasis control in Africa: 8 years after World Health Assembly resolution 54.19. Parasitology 136, 1677-1681.

Seubert, J., Pohlke, R. and Loebich, F. (1977). Synthesis and properties of praziquantel, a novel broad spectrum anthelmintic with excellent activity against schistosomes and cestodes. Experientia 33, 1036-1037.

Simoonga, C., Utzinger, J., Brooker, S., Vounatsou, P., Appleton, C. C., Stensgaard, A. S., Olsen, A. and Kristensen, T. K. (2009). Remote sensing, geographical information system and spatial analysis for schistosomiasis epidemiology and ecology in Africa. Parasitology 136, 1683-1693.

Singer, B. H. and Castro, M. C. (2007). Bridges to sustainable tropical health. Proceedings of the National Academy of Sciences of the United States of America 104, 16038-16043.

Steinmann, P., Keiser, J., Bos, R., Tanner, M. and Utzinger, J. (2006). Schistosomiasis and water resources development: systematic review, meta-analysis, and estimates of people at risk. Lancet Infectious Diseases 6, 411-425.

Stensgaard, A. S., Saarnak, C. F. L., Utzinger, J., Vounatsou, P., Simoonga, C., Mushinge, G., Rahbek, C., Mohlenberg, F. and Kristensen, T. K. (2009). Virtual globes and geospatial health: the potential of new tools in the management and control of vector-borne diseases. Geospatial Health 3, 127-141.

Stothard, J. R., Webster, B. L., Weber, T., Nyakaana, S., Webster, J. P., Kazibwe, F., Kabatereine, N. B. and Rollinson, D. (2009). Molecular epidemiology of Schistosoma mansoni in Uganda: DNA barcoding reveals substantial genetic diversity within Lake Albert and Lake Victoria populations. Parasitology 136, 1813-1824.

Tchuem Tchuenté, L. A. and N'Goran, E. K. (2009). Schistosomiasis and soil-transmitted helminthiasis control in Cameroon and Côte d'Ivoire: implementing control on a limited budget. Parasitology 136, 1739-1745.

The Schistosoma japonicum Genome Sequencing and Functional Analysis Consortium (2009). The Schistosoma japonicum genome reveals features of host-parasite interplay. Nature 460, 345-351.

Utzinger, J., Bergquist, R., Xiao, S. H., Singer, B. H. and Tanner, M. (2003). Sustainable schistosomiasis control - the way forward. Lancet 362, 1932-1934.

Utzinger, J. and de Savigny, D. (2006). Control of neglected tropical diseases: integrated chemotherapy and beyond. PLoS Medicine 3, e112.

Utzinger, J., Raso, G., Brooker, S., de Savigny, D., Tanner, M., Ørnbjerg, N., Singer, B. H. and N'Goran, E. K. (2009). Schistosomiasis and neglected tropical diseases: towards integrated and sustainable control and a word of caution. Parasitology 136, 1859-1874.

Utzinger, J., Zhou, X. N., Chen, M. G. and Bergquist, R. (2005). Conquering schistosomiasis in China: the long march. Acta Tropica 96, 69-96.

Vounatsou, P., Raso, G., Tanner, M., N'Goran, E. K. and Utzinger, J. (2009). Bayesian geostatistical 
modelling for mapping schistosomiasis transmission. Parasitology 136, 1695-1705.

Wang, L., Utzinger, J. and Zhou, X. N. (2008).

Schistosomiasis control: experiences and lessons from China. Lancet 372, 1793-1795.

Webster, J. P., Koukounari, A., Lamberton, P. H., Stothard, J. R. and Fenwick, A. (2009). Evaluation and application of potential schistosome-associated morbidity markers within large-scale mass chemotherapy programmes. Parasitology 136, 1789-1799.

WHO (1985). The control of schistosomiasis : report of a WHO expert committee. WHO Technical Report Series No. 728, 1-113. Geneva.

WHO (2002). Prevention and control of schistosomiasis and soil-transmitted helminthiasis : report of a WHO expert committee. WHO Technical Report Series No. 912, 1-57.

WHO (2006). Preventive chemotherapy in human helminthiasis : coordinated use of anthelminthic drugs in control interventions: a manual for health professionals and programme managers. World Health Organization, Geneva.

Wolff, T. and Malewezi, J. G. (1989). Organization and decentralization of the Malawi National Bilharzia Control Programme. Tropical Medicine and Parasitology 40, 201-204.

Zhou, X. N., Wang, L. Y., Chen, M. G., Wu, X. H., Jiang, Q. W., Chen, X. Y., Zheng, J. and Utzinger, J. (2005). The public health significance and control of schistosomiasis in China - then and now. Acta Tropica 96, 97-105. 